\title{
A COMPARATIVE GENETIC STUDY ON EXPLOITED VS. UNPERTURBED WILD POPULATIONS OF HELIX POMA- TIA (L., 1758): PRELIMINARY RESULTS
}

\author{
Ana-Maria Krapal', Oana Paula Popa ${ }^{1}$, Voichița Gheoca ${ }^{2}$ \\ 1“Grigore Antipa” National Museum of Natural History, Bucharest, Romania, ana.krapal@anti- \\ pa.ro, oppopa@antipa.ro \\ 2"Lucian Blaga" University of Sibiu, Faculty of Sciences, Department of Ecology and Environ- \\ ment Protection, Sibiu, Romania, vgheoca@yahoo.com
}

\begin{abstract}
Helix pomatia is one of the most well known species of land snails across Europe and it presents economical importance due to its consumption as food. The preliminary results of the genetic comparison between two populations, one of them under the pressure of exploitation, are presented here. As expected, most indices revealed a disequilibrium in the exploited population, with the exeption of the allelic pattern which was similar among the two studied populations.
\end{abstract}

\section{Introduction}

The Roman snail Helix pomatia Linnaeus, 1758 is a quite well-known land snail species due to its distribution across almost the whole Europe [7]. It is also one of the biggest species, its shell reaching $4.5 \mathrm{~cm}$ [7]. For this reason, Helix pomatia is farmed for consumption, together with $H$. lucorum and $H$. aspersa, and it is highly appreciated for its taste. Helix pomatia is commonly consumed in the Mediterranean region and was introduced to this end in countries such as Great Britain, the Netherlands, Sweden, Denmark [14] and wild populations are also exploited. In Romania, wild H. pomatia populations are also exploited since the 1950' [5]. In the EU, the Roman snail is a protected species and is included in the 92/43/EEC Habitats Directive, Annex V and is mentioned in the Berna Convention, Annexe III.

The species has been extensively analysed in terms of its biology and ecology, which are more important for achieving optimal conditions necessary for successful growth and reproduction of individuals in snail farms. Land snails in general are sensitive to climate variations, and it has been shown that $H$. pomatia populations are easily affected by extreme opposite phenomena (e.g., floods, droughts) [6]. Until recently, the species in the Helix genus were barely studied from a population genetics and phylogeographic point of view. The most recent genetic studies refer to the phylogeography and phylogeny of the Helicidae family or the species within genus Helix [4, 8, 9, 10, 11].

The present study analyses the genetic structure of two wild populations of $H$. pomatia from Romania using DNA microsatellite markers. One of the populations is constantly exploited, while the other is left unperturbed. The population genetics analyses undertaken in this study will be able to assess the genetic state of health of the analysed populations and to highlight possible threatened populations/subpopulations of this species. 


\section{Matherials and methods}

Two wild populations of $H$. pomatia from Romania were chosen for this study. One population, BT (Biertan, Sibiu County), is constantly being exploited, while the population MAD (Măda, Hunedoara County) is completely unperturbed. 30 mature individuals were collected from each population and conserved in 70\% ethanol. Complete genomic DNA was extracted from foot tissue using the ISOLATE II Genomic DNA Kit (Bioline, London, UK), according to producer specifications. Nine microsatellite markers were used for genotyping both populations: HP50, HP97, HP186, HP207, HP228, HP503, HP535, HP558, HP612, with the PCR genotyping reactions and conditions were used as described in Krapal et al. (2016). The genotyping was performed on an LI-COR 4300L genetic analyzer (LI-COR Biosciences, Nebraska, USA) and the SagaGT v3.1 was used for scoring alleles.

GenAlEx v6.501 [12, 13] was used to test for Hardy-Weinberg equilibrium at each locus and to estimate the number of alleles (NA), along with observed (Ho) and expected heterozygosity $(\mathrm{He})$. The fixation index (F) and the genetic differentiation between the two populations were also estimated using GenAlEx. The effective population size $(\mathrm{Ne})$ for each population was estimated using the Linkage Disequilibrium method implemented in NeEstimator 2.01 [2], with a Jacknife at 0,02\%. GENETIX 4.05 [1] was used for the Principal Coordinates Analysis (PCoA). Population genetic structure was assessed using a Bayesian Markov Chain Monte Carlo model (MCMC) implemented in STRUCTURE v2.3.4 [15]. Ten runs were performed for each number of populations $(\mathrm{K})$ set from 1 to 4 . Burn-in time and MCMC replication number were set to 150,000 and 750,000 generations, respectively, for each run. The optimal number of clusters was identified using both the Evanno method $(\Delta K)[3]$ and the highest probability for $\mathrm{K}$ [15] following on the CLUMPAK online platform (https://clumpak.tau.ac.il).

\section{Results and discussion}

All loci were polymorphic in all genotyped populations, with a similar allelic pattern. For the BT population, 3 out of 9 single locus tests showed a significant deviation form Hardy-Weinberg Equilibrium $(\mathrm{p}<0.01)$ after Bonferroni correction, while for MAD population only 1 out of 9 single locus tests showed a slight deviation from HWE after applying the same correction.

The inbreeding level was assessed by the inbreeding coefficient (Fis), values close to 0 indicating a random mating process. The inbreeding was higher in the BT population (Fis = $0.230, \mathrm{SE}=0.106)$ than in the MAD population $(\mathrm{Fis}=0.009, \mathrm{SE}=0.071)$, most likely due to the smaller number of adult individuals that mate.

The genetic differentiation between the two populations was moderate to high as evidenced by the Fst values $(\mathrm{Fst}=0.127)$. This result was also evidenced by the analysis of molecular variance (AMOVA) which indicated an interpopulational genetic variability of $13 \%$ as compared with the intrapopulational genetic variability of $87 \%$. 

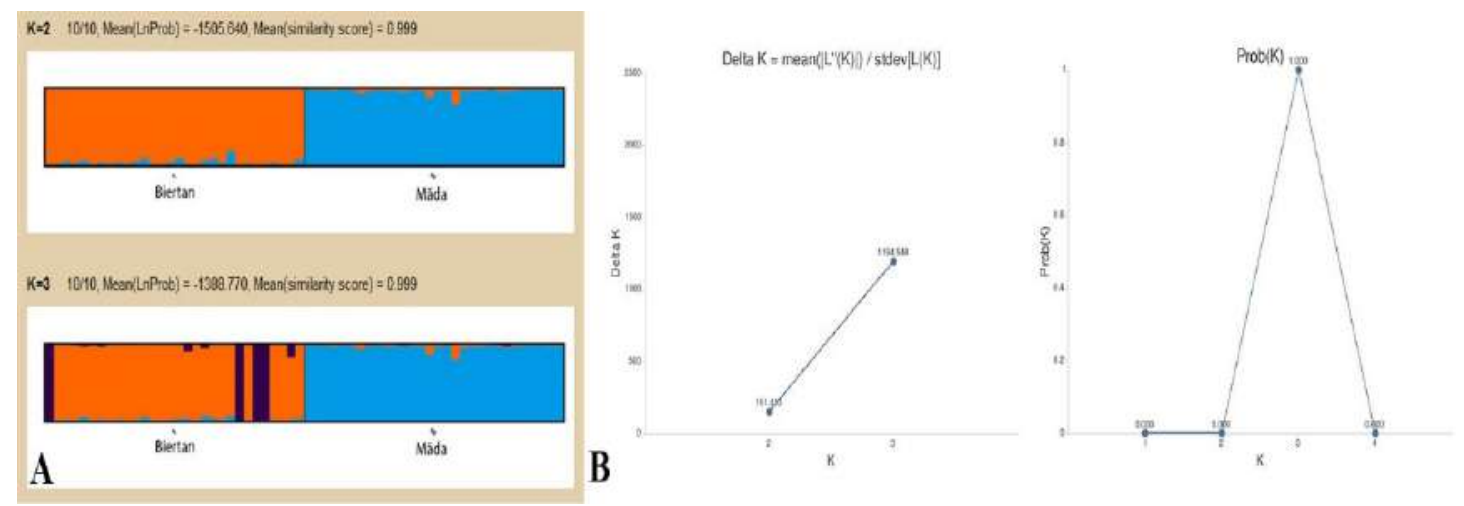

Figure 1. (A) STRUCTURE plot describing the population structure using $K=3$ as most probable number of genetic groups. (B) Probability by $K$ graph using median values of $\operatorname{Ln}(\operatorname{Pr}$ Data) the $k$ for which $\operatorname{Pr}(K=k)$ is highest (Pritchard et al., 2000) and DeltaK graph - optimal $K$ by Evanno (Evanno et al., 2005).

The effective population size $(\mathrm{Ne})$ represents the estimated number of individuals that reproduce within a population. The MAD population seems to be healthier with $\mathrm{Ne}=113.5(95 \%$ $\mathrm{CI}=41.7$-infinite), while the BT population is more at risk in case of disease or other such events $(\mathrm{Ne}=6.6,95 \% \mathrm{CI}=4.7-8.7)$.

The genetic structure analysis has shown a separation of the samples in 3 clusters $(K=3)$, with the BT population split into 2 subpopulations (fig. 1). The same structuring was evidenced through the Principal Coordinates Analysis (PCoA), a small group of individuals from the BT population being clearly grouped in a separate cluster (fig. 2). The clustering of the BT population into 2 separate groups might signify a possible habitat fragmentation.

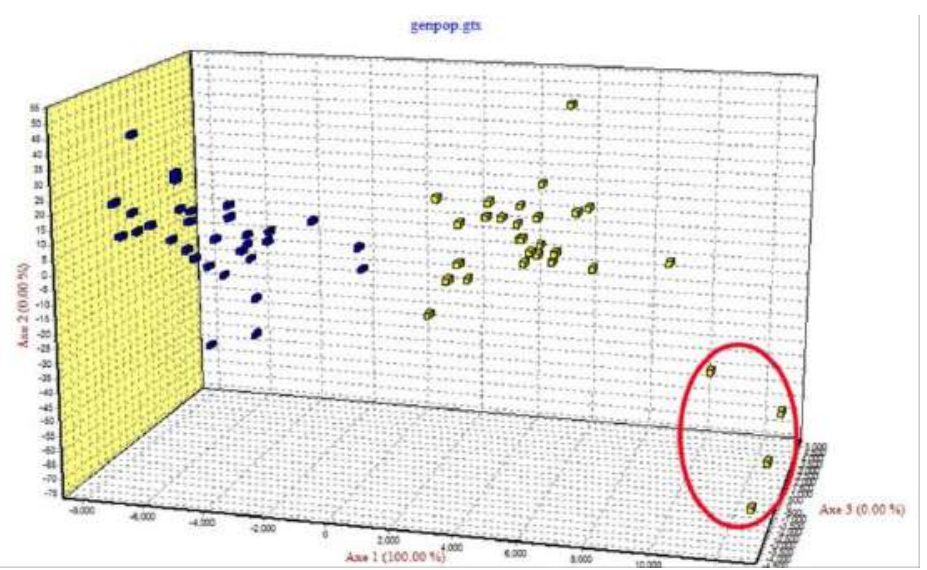

Figure 2. Principal Coordinates Analysis (PCoA) via Covariance matrix with data standardization - PCoA of genetic distances between individuals; BT in yellow, MAD in blue. 
The genetic differences between the two populations shown by the HWE, the Fst values and the clear genetic structuring highlight the effects of constant pressures that the BT population is under. The constant exploitation of some populations, in the current context of climate changes (e.g., drought, sudden floods, high temperatures), represents an additional pressure for populations that may be threatened and become extinct in the absence of protective measures. The genetic parameters used in this study can be used to identify the vulnerable populations of this species in order to take measures for their protection.

\section{Bibliography}

1. Belkhir K., Borsa P., Chikhi L., Raufaste N. \& Bonhomme F. (1996-2004). GENETIX 4.05, logiciel sous Windows TM pour la génétique des populations. Laboratoire Génome, Populations, Interactions, CNRS UMR 5000, Université de Montpellier II, Montpellier (France).

2. Do, C., Waples, R. S., Peel, D., Macbeth, G. M., Tillett, B. J., \& Ovenden, J. R. (2014). NeEstimator v2: re-implementation of software for the estimation of contemporary effective population size (Ne) from genetic data. Molecular Ecology Resources, 14(1), 209-214. https://doi. org/https://doi.org/10.1111/1755-0998.12157

3. Evanno, G., Regnaut, S., \& Goudet, J. (2005). Detecting the number of clusters of individuals using the software structure: a simulation study. Molecular Ecology, 14(8), 2611-2620. https:// doi.org/https://doi.org/10.1111/j.1365-294X.2005.02553.x

4. Fiorentino, V., Manganelli, G., Giusti, F., \& Ketmaier, V. (2016). Recent expansion and relic survival: Phylogeography of the land snail genus Helix (Mollusca, Gastropoda) from south to north Europe. Molecular Phylogenetics and Evolution, 98, 358-372. https://doi.org/https://doi. org/10.1016/j.ympev.2016.02.017

5. Gheoca, V. (2013). Edible land snail Helix pomatia's exploitation in Central Romania - legislation, evolution, perspectives. Advances in Environment, Ecosistems \& Sustainable Tourism, 1, 144-149.

6. Gheoca, V., \& Costea, M. (2013). Land snails vulnerability to climatic conditions variation the case of two species Fruticicola fruticum Müller and Helix pomatia Linnaeus. In V. Marascu-Klein, F. V. Panaitescu, \& M. Panaitescu (Eds.), Proceedings of the 11th International Conference on Energy, Ecosystems and Development EED 2013, Braşov, Romania (pp. 150-155).

7. Grossu, A. V. (1983). Gastropoda Romaniae, Ordo Stylommatophora, Suprafamiliile: Arionacea, Zonitacea, Ariophantacea și Helicacea. Editura Litera.

8. Korábek, O., Juřičková, L., \& Petrusek, A. (2014). Resurrecting Helix straminea, a forgotten escargot with trans-Adriatic distribution: first insights into the genetic variation within the genus Helix (Gastropoda: Pulmonata). Zoological Journal of the Linnean Society, 171(1), 72-91. https://doi.org/10.1111/zoj12122

9. Korábek, O., Juřičková, L., \& Petrusek, A. (2016). Splitting the Roman snail Helix pomatia Linnaeus, 1758 (Stylommatophora: Helicidae) into two: redescription of the forgotten Helix thessalica Boettger, 1886. Journal of Molluscan Studies, 82(1), 11-22. https://doi.org/10.1093/ mollus/eyv048

10. Korábek, O., Petrusek, A., \& Juřičková, L. (2018). Glacial refugia and postglacial spread of an iconic large European land snail, Helix pomatia (Pulmonata: Helicidae). Biological Journal of the Linnean Society, 123(1), 218-234. https://doi.org/10.1093/biolinnean/blx135

11. Korábek, O., Petrusek, A., Neubert, E., \& Juřičková, L. (2015). Molecular phylogeny of the genus Helix (Pulmonata: Helicidae). Zoologica Scripta, 44(3), 263-280. https://doi.org/https:// doi.org/10.1111/zsc. 12101 
12. Peakall, R., \& Smouse, P. E. (2006). GENALEX 6: genetic analysis in Excel. Population genetic software for teaching and research. Molecular Ecology Notes, 6(1), 288-295. https://doi. org/https://doi.org/10.1111/j.1471-8286.2005.01155.x

13. Peakall, R., \& Smouse, P. E. (2012). GenAlEx 6.5: genetic analysis in Excel. Population genetic software for teaching and research--an update. Bioinformatics (Oxford, England), 28(19), 2537-2539. https://doi.org/10.1093/bioinformatics/bts460

14. Pollard, E. (1975). Aspects of the Ecology of Helix pomatia L. Journal of Animal Ecology, 44(1), 305-329. https://doi.org/10.2307/3865

15. Pritchard, J. K., Stephens, M., \& Donnelly, P. (2000). Inference of Population Structure Using Multilocus Genotype Data. Genetics, 155(2), 945 LP - 959. 